\title{
A LIAPUNOV INEQUALITY FOR LINEAR HAMILTONIAN SYSTEMS
}

\author{
Steve Clark * AND DON Hinton
}

Abstract. A Liapunov type inequality is proved for a linear Hamiltonian system. This inequality allows estimates of intervals of disconjugacy. The inequality is particularly applicable to equations with oscillatory coefficients. A new criterion of stability is given for a differential equation with periodic coefficients.

Mathematics subject classification (1991): 26D10, 34C10, 34C25.

Key words and phrases: Liapunov inequality, disconjugacy, Hamiltonian system.

\section{REFERENCES}

[1] R. P. Agarwal and P. Y. H. Pang, Opial Inequalities with Applications in Differential and Difference Equations, Kluwer Academic Publishers, Dordrecht (1995).

[2] R. W. Brockett, Finite Dimensional Linear Systems, John Wiley and Sons, New York (1970).

[3] R. C. BRown AND D. B. Hinton, Opial's inequality and oscillation of 2 nd order equations, Proc. Amer. Math. Soc. 125 (1997), 1123-1129.

[4] J. CALVERT, Some generalizations of Opial's inequality, Proc. Amer. Math. Soc. 18 (1967), 72-75.

[5] SuI-SAng CHEng,, Lyapunov inequalities for diffential and difference equations, Fasc. Math. 23 (1991), 25-41.

[6] W. A. Coppel, Disconjugacy, Springer-Verlag Lecture Notes in Mathematics 220 (Berlin, 1971).

[7] M. S. P. EASTHAM, The Spectral Theory of Periodic Diffeential Equations, Scottish Academic Press, Edinburgh (1973).

[8] P. Hartman, Ordinary Differential Equations, John Wiley and Sons, New York (1964).

[9] W. T. REID, A matrix Liapunov inequality, J. Math. Anal. Appl. 32 (1970), 424-434.

[10] Riccati differential equations, Academic Press, New York (1972).

[11] A generalized Liapunov inequality, J. Diff. Eqs. 13 (1973), 182-196.

[12] Interrelations between a trace formula and Liapunov type inequalities, J. Diff. Eqs. 23 (1977), 448-458.

[13] Sturmian theory for ordinary differential equaitons, Applied Math. Sciences 31 (Springer-Verlag, Berlin, 1980).

[14] V. A. Yakubovich And V. M. Starzhinskit, Linear Differential Equations with Periodic Coefficients, John Wiley and Sons, New York Vol. II (1975). 